\title{
Oral cancer susceptibility associated with the CYP1A1 and GSTM1 genotypes in Chilean individuals
}

\author{
KARINA CORDERO $^{1}$, IRIS ESPINOZA ${ }^{2}$, DANTE CACERES ${ }^{1,3}$, ANGELA ROCO $^{1,4}$, CARLA MIRANDA $^{1,4}$, \\ VALENTINA SQUICCIARINI $^{1}$, PAULA SANTANDER ${ }^{1}$, KUEN LEE $^{1}$, IVÁN SAAVEDRA ${ }^{1}$ and LUIS QUIÑONES ${ }^{1}$ \\ ${ }^{1}$ Center of Pharmacological and Toxicological Research (IFT), Institute of Biomedical Sciences, Faculty of Medicine; \\ ${ }^{2}$ Department of Oral Pathology, Faculty of Odontology; ${ }^{3}$ Epidemiology Division, School of Public Health, \\ Faculty of Medicine, University of Chile; ${ }^{4}$ San Juan de Dios Hospital, Santiago, Chile
}

Received December 23, 2009; Accepted March 3, 2010

DOI: 10.3892/ol_00000097

\begin{abstract}
Polycyclic aromatic hydrocarbons (PAHs) contained in tobacco smoke acquire carcinogenicity following their activation by xenobiotic-metabolizing enzymes to highly reactive metabolites. The cytochrome P4501A1 (CYP1A1) enzyme is central to the metabolic activation of these PAHs, and GSTM1 is the main enzyme responsible for its detoxification. CYP1A1 and GSTM1 polymorphisms were evaluated in 124 Chilean healthy controls and 48 oral cancer patients through PCR-based restriction fragment length polymorphism. In the healthy controls, frequencies of the CYP1A1 variant alleles for m1 (CYP1A1*2A) and the GSTM1null genotype were found to be 0.25 and 0.19 , respectively. In the oral cancer patients, these frequencies were 0.33 and 0.50 , respectively. Thus, the GSTM1 and $\mathrm{m} 1$ rare alleles were significantly more frequent in the oral cancer patients compared to the controls. The estimated relative risk for oral cancer associated with the single genotype CYP1A1 or GSTM1 was 2.08 for wt $/ \mathrm{m} 1,1.04$ for $\mathrm{m} 1 / \mathrm{m} 1$ and 4.16 for the GSTM1null genotype. For smokers, the estimated relative risk (adjusted by age and gender) was higher in the individuals carrying the $\mathrm{m} 1$ allele of CYP1A1 [wt $/ \mathrm{ml}$ : odds ratio $(\mathrm{OR})=5.68, \mathrm{P}=0.0080 ; \mathrm{ml} / \mathrm{ml}: \mathrm{OR}=7.77$, $\mathrm{P}=0.0420]$ or GSTM1null genotype $(\mathrm{OR}=20.81, \mathrm{P}<0.0001)$. Combined genotypes CYP1A1 and GSTM1 increased the risk significantly (wt/m1/GSTM1null: $\mathrm{OR}=19.14, \mathrm{P}=0.0030 ; \mathrm{ml} /$ m1/GSTM1null: OR=21.39, $\mathrm{P}=0.0130)$. Taken together, these findings suggest that Chilean individuals carrying single or combined GSTM1 and CYP1A1 polymorphisms may be more susceptible to oral cancer induced by environmental tobacco smoking.
\end{abstract}

Correspondence to: Dr Luis Quiñones, Center of Pharmacological and Toxicological Research (IFT), Molecular and Clinical Pharmacology Program, Biomedical Sciences Institute, Faculty of Medicine, University of Chile, P.O. Box 70111, Santiago 7, Chile E-mail: lquinone@med.uchile.cl

Key words: oral cancer, CYP1A1, GSTM1, polymorphisms, genotype

\section{Introduction}

Polycyclic aromatic hydrocarbons (PAHs) are environmental compounds ubiquitously distributed in smoked foods, tobacco smoke and the urban outdoor environment in large cities (1). PAHs acquire carcinogenicity following activation by xenobiotic-metabolizing enzymes to highly reactive metabolites (2). PAHs are able to attack cellular DNA, and are therefore believed to be responsible for an elevated risk of certain types of cancer in different population groups $(3,4)$, This is particularly true in those types of cancer directly related to the respiratory tract such as lung (5-7) and oral cancers (8-10), but also in other types such as prostate, stomach and colorectal (11-14). Cytochrome P450 (CYP) enzymes are pivotal to the metabolic activation of PAHs to epoxide intermediates. These intermediates are converted into the ultimate carcinogens, diol-epoxides, via epoxide hydrolase. CYP1A1 was believed to be the most important enzyme catalyzing activation of these pro-carcinogenic PAHs (15). The entire CYP1A1 gene was sequenced (16) and four separate point mutations were reported. One polymorphism in the 30 -non-coding region is named $\mathrm{m} 1$ (17), and another within exon 7 is named $\mathrm{m} 2$ (18). Polymorphism $\mathrm{m} 3$ is mutated in the 3 '-flanking region which appears to be specific to individuals of African descent (19). On the other hand, m4, located in exon 7, which exchanges threonine 461 with asparagine, is present in German, Polish and Turkish populations $(20,21)$.

GSTM1, an enzyme belonging to a family of glutathione transferases, is responsible for the inactivation of PAHs. This enzyme has a polymorphic form with a deficient activity and is unevenly distributed among ethnic groups, particularly in South American populations (22-25). This variant is present in approximately $50 \%$ of Caucasian populations and $31 \%$ of Japanese individuals (25). Lack of detoxification activity was shown to be caused by an inherited homozygous deletion of the GSTM1 gene (26). This form has been related to several types of cancer with ethnic variations (12,27,28). Combined polymorphisms of CYP1A1 and GSTM1 have been associated with an increased cancer risk in prostate, oral, gastric, lung, skin and colorectal tissues (6,11,29-33).

It is likely that individual variations in metabolic activities in each phase or in the coordination of the two phases regulate 
the clearance of DNA toxic metabolites and may partially be responsible for individual host susceptibility of tobaccooriginated PAH exposure-related cancer.

On the other hand, oral cancer, a disease associated with a smoking habit, is the sixth most common malignant neoplasia in the world, whose high incidence represents a significant problem in several countries (34). In Chile, the second cause of death is cancer of the lung, trachea and bronchia, and almost 5 million people smoke $>8$ cigarettes per day (men, 8.8; women, 7.3$)$. In $2003,22 \%$ of the total mortality was attributable to tobacco (www.misnal.cl), and $1.6 \%$ of mortality from cancer was due to oral cancer with the squamous spinocellular carcinoma being the most frequent $(90 \%)$. The incidence of this neoplasia has increased in women from 1980 to 2002, and has been associated with a $100 \%$ increase in smoking habits in this group (35).

We previously demonstrated a positive association between CYP1A1 and GSTM1 polymorphisms in prostate, stomach and lung cancer $(11,13,30)$. This study investigated the distribution of single and combined genotypes of CYP1A1*2A and GSTM1null polymorphism in two Chilean groups (healthy controls and oral cancer patients). The manner in which associated risk for smoking-related oral cancers is modified by the combination of CYP1A1 and GSTM1 polymorphisms was also investigated.

\section{Materials and methods}

Study population. Patients diagnosed with oral cancer were recruited from the National Institute of Cancer, and controls were recruited throughout the Santiago, Chile area. Blood samples were obtained from 124 healthy controls (57 women and 67 men, $50.4 \pm 14$ years of age) and 48 unrelated oral cancer patients ( 16 women and 32 men, $62.3 \pm 10$ years of age).

A smoker was defined as a person with a smoking index (SI) $>800$ (or Brinkman index; cigarettes/day x 365) (30). At the time of the analysis, both present and former smokers were considered as smokers.

Both control and cancer patients were interviewed regarding smoking habits, use of medication, previous history of cancer in related family members and exposure to occupational, outdoor and indoor carcinogenic pollutants. Oral cancer patients were all previously diagnosed histologically, and their medical records were available from the National Institute of Cancer, Santiago.

Samples were obtained following informed written consent. The study was approved by the Ethics Board of the Faculty of Medicine of the University of Chile and the National Cancer Institute.

Genotyping analysis. According to the recommended nomenclature of human polymorphic genes, the CYP1A1 wild-type allele was termed CYP1A1*1A, the MspI or $\mathrm{m} 1$ allele was termed CYP1A1*2A (http://www.imm.ki.se/CYPalleles) and the GSTM1 deletion was null/null or $\%$. CYP1A1 and GSTM1 polymorphisms in the studied group were found to be in Hardy-Weinberg equilibrium.

DNA was isolated from peripheral blood samples using a genomic DNA extraction kit (Roche Diagnostics $\mathrm{GmbH}$,

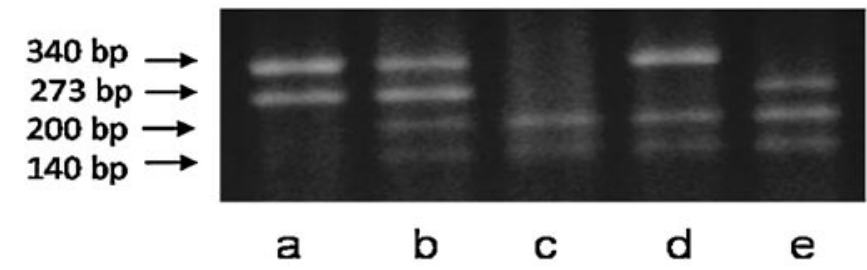

Figure 1. PCR-RFLP genotype analysis of selected subjects. (a) wt/wt/ GSTM1(+/+); (b) $\mathrm{wt} / \mathrm{m} 1 / \operatorname{GSTM1}(+/+)$; (c) $\mathrm{m} 1 / \mathrm{m} 1 / \operatorname{GSTM} 1(-/)$; (d) $\mathrm{wt} / \mathrm{m} 1 /$ $\operatorname{GSTM} 1(+)$ and $(\mathrm{e}) \mathrm{m} 1 / \mathrm{m} 1 / \mathrm{GSTM} 1(++)$.

Mannheim, Germany). PCR-based restriction fragment length polymorphism (RFLP) with primers C44 and C47 (17) yielded a fragment of $340 \mathrm{bp}$. The GSTM1 genetic polymorphism was determined using primers described by Ambrosone et al (36). The primers were used simultaneously with CYP1A1 primers as the internal control for amplification. The presence of the GSTM1null genotype was determined by the absence of a 273-bp fragment product. The samples were then analyzed by electrophoresis in agarose 2 or $6 \%$ polyacrylamide gels (Bio-Rad Lab., Richmond, CA, USA). The samples were submitted to separate amplifications followed by digestion with the MspI restriction enzyme (Gibco Brl; Life Technologies Inc., Gaithersburg, MD, USA) at $37^{\circ} \mathrm{C}$ for $3 \mathrm{~h}$.

\section{Statistics: Study design}

Analytic methodology. Genotype frequencies and the $95 \%$ confidence interval (CI) for CYPIAI and GSTM1 were calculated as the proportion of individuals with a given genotype divided by the total number of participants. For CYPIAl, allele frequencies and the $95 \% \mathrm{CI}$ were calculated as the number of alleles divided by the number of chromosomes. The test for Hardy-Weinberg equilibrium was also conducted. To explore the possible associations between the GSTM1 and CYPIAl genetic polymorphisms and oral cancer risk, as well as to evaluate the putative modification by these genotypes on smoking, the data were cross-classified using a $2 \times 4$ table. The relationship between these polymorphic genes and smoking and oral cancer risk was examined using odds ratios (OR) with 95\% CI and Woolf's method in an unconditional logistical model. Associations were evaluated using a priori low-risk bivariate genotype combinations (wt/wt and GSTM1 present) in non-smokers as a common reference group. Finally, the OR is presented as unadjusted and adjusted by age and gender. Statistical analyses were performed using Stata version 10.0 software.

\section{Results}

A representative profile of the simultaneous genotypification of CYP1A1*2A ( $\mathrm{m} 1$ allele) and GSTM1null polymorphisms in oral cancer patients is shown in Fig. 1. Genotype distributions and frequencies for the CYP1A1*2A and GSTM1 genotypes in healthy controls and oral cancer patients are shown in Table I. For CYP1A1*2A genotypes, the presence of allelic variant $m l$ was more frequent in the oral cancer cases than in the controls (1.36-fold). Similarly, the frequency of the homozygous deletions of GSTM1 loci was 2.6-fold higher in the oral cancer 
Table I. Genotype frequencies of polymorphic variants of CYP1A1 and GSTM1, and the smoking habits in oral cancer patients and control subjects in a sample of Chilean individuals.

\begin{tabular}{|c|c|c|c|c|c|c|c|}
\hline \multirow[t]{2}{*}{ Genotypic variant } & \multicolumn{2}{|c|}{ Control } & \multicolumn{2}{|c|}{ Cancer } & \multirow[t]{2}{*}{ OR } & \multirow[t]{2}{*}{$95 \% \mathrm{CI}$} & \multirow[t]{2}{*}{ P-value } \\
\hline & $\mathrm{n}$ & $\%$ & $\mathrm{n}$ & $\%$ & & & \\
\hline \multicolumn{8}{|l|}{ CYP1A1 } \\
\hline$w t / w t$ & 75 & 60.48 & 22 & 45.83 & 1.00 & & \\
\hline$w t / m 1$ & 36 & 29.03 & 22 & 45.83 & 2.08 & $1.00-4.29$ & 0.0422 \\
\hline$m 1 / m 1$ & 13 & 10.48 & 4 & 8.33 & 1.04 & $0.30-3.56$ & 0.9389 \\
\hline \multicolumn{8}{|l|}{ Allelic variant } \\
\hline$w t$ & 186 & 75.00 & 66 & 68.70 & 1.00 & & \\
\hline$m 1$ & 62 & 25.00 & 30 & 31.30 & 1.36 & $0.77-2.35$ & 0.2401 \\
\hline \multicolumn{8}{|l|}{ GSTM1 } \\
\hline Positive & 100 & 80.65 & 24 & 50.00 & 1.00 & & \\
\hline Null & 24 & 19.35 & 24 & 50.00 & 4.16 & $1.95-8.89$ & 0.0001 \\
\hline \multicolumn{8}{|l|}{ Smoking } \\
\hline No & 60 & 48.39 & 7 & 14.58 & 1.00 & & \\
\hline Yes & 64 & 51.61 & 41 & 85.42 & 5.49 & $2.17-13.83$ & $<0.0001$ \\
\hline
\end{tabular}

OR, odds ratio; CI, confidence interval; wt, wild-type.

Table II. Joint effect of genotypic polymorphic variants of CYP1A1 and GSTM1 and smoking in oral cancer patients and control subjects in a sample of Chilean individuals (adjusted by age and gender).

\begin{tabular}{|c|c|c|c|c|c|c|c|c|}
\hline \multirow[t]{2}{*}{ Smoking } & \multirow[t]{2}{*}{ Genotypic variant } & \multicolumn{2}{|c|}{ Cancer } & \multicolumn{2}{|c|}{ Control } & \multirow[t]{2}{*}{ OR } & \multirow[t]{2}{*}{$95 \% \mathrm{CI}$} & \multirow[t]{2}{*}{ P-value } \\
\hline & & $\mathrm{n}$ & $\%$ & $\mathrm{n}$ & $\%$ & & & \\
\hline & CYP1A1 & & & & & & & \\
\hline- & $w t / w t$ & 4 & 8.33 & 35 & 28.23 & 1.00 & & \\
\hline- & $w t / m 1$ & 3 & 6.25 & 15 & 12.10 & 1.51 & $0.27-8.23$ & 0.6310 \\
\hline- & $\mathrm{ml} / \mathrm{ml}$ & 0 & 0.00 & 10 & 8.06 & 0.00 & -- & 0.2956 \\
\hline+ & $w t / w t$ & 18 & 37.50 & 40 & 32.26 & 3.89 & $1.08-13.98$ & 0.0370 \\
\hline+ & $w t / m 1$ & 19 & 39.58 & 21 & 16.94 & 5.68 & $1.57-20.44$ & 0.0080 \\
\hline \multirow[t]{2}{*}{+} & $\mathrm{ml} / \mathrm{ml}$ & 4 & 8.33 & 3 & 2.42 & 7.77 & $1.07-55.91$ & 0.0420 \\
\hline & GSTM1 & & & & & & & \\
\hline- & positive & 4 & 8.33 & 48 & 38.71 & 1.00 & & \\
\hline- & null & 3 & 6.25 & 12 & 9.68 & 2.75 & $0.48-15.79$ & 0.1730 \\
\hline+ & positive & 20 & 41.67 & 52 & 41.94 & 3.57 & $1.05-12.09$ & 0.0410 \\
\hline+ & null & 21 & 43.75 & 12 & 9.68 & 20.81 & $5.45-79.34$ & $<0.0001$ \\
\hline & CYP1A1/GSTM1 & & & & & & & \\
\hline- & $w t / w t / p o s i t i v e$ & 2 & 4.17 & 32 & 25.81 & 1.00 & & \\
\hline+ & wt/ml/null & 7 & 14.58 & 5 & 4.03 & 19.14 & $2.82-129.95$ & 0.0030 \\
\hline+ & $\mathrm{ml} / \mathrm{ml} / \mathrm{null}$ & 4 & 8.33 & 2 & 1.61 & 21.39 & $1.92-237.68$ & 0.0130 \\
\hline
\end{tabular}

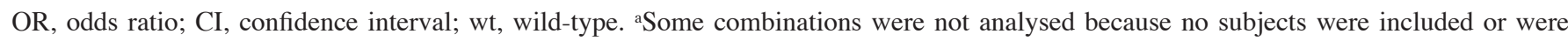
physiologically relevant.

patients than in the controls. Table I also shows the oral cancer risk associated with polymorphisms in the GSTM1 and CYP1A1 genes with reference to the wild-type genotype. For the CYP1A $1 * 2 \mathrm{~A}$ polymorphism, the heterozygous genotype was present in $45.83 \%$ of the cancer patients and in $29.03 \%$ of the controls $(\mathrm{OR}=2.08, \mathrm{P}=0.0422)$, whereas the homozygous mutant genotype was present in $8.33 \%$ of the cancer patients and in $10.48 \%$ of controls $(\mathrm{OR}=1.04, \mathrm{P}=0.939)$.

The CYP1A1*2A m1 allele was present in $31.3 \%$ of the cancer patients and in $25 \%$ of the controls. As anticipated, the 
frequency of the $\mathrm{m} 1$ allelic variant in the controls was higher than the frequency in Caucasians and lower than the frequency in Asians (25). The GSTM1null genotype was found in 50\% of the oral cancer patients and $19.35 \%$ of the controls $(\mathrm{OR}=4.16$, $\mathrm{P}=0.0001)$. Table II shows the estimated relative risks for oral cancer in Chilean patients associated with single or combined CYP1A1 and GSTM1 genotypes, in combination with or without a smoking habit. The m1/GSTM1null genotype in smokers was associated with a higher risk of oral cancer compared to that in wt/wt/positive non-smoking subjects. Notably, the combination of $\mathrm{m} 1 / \mathrm{m} 1 / \mathrm{GSTM} 1$ null conferred a higher risk $(21.39, \mathrm{P}=0.003)$ compared to that of $\mathrm{w} 1 / \mathrm{m} 1$ / GSTM1null combination (19.14, $\mathrm{P}=0.0130)$.

\section{Discussion}

In this study, the CYP1A1 and GSTM1 genotypes were analyzed in 48 Chilean oral cancer patients and 124 healthy controls. The frequencies of $\mathrm{m} 1$ and the GSTM1null genotype were higher in oral cancer patients compared to the controls. Moreover, whether the presence of the CYP1A1 and GSTM1 polymorphisms is associated with oral cancer susceptibility is still controversial. A recent report found no relationship between CYP1A1 and/or GST polymorphisms and oral cancer in an Indian population (10). However, the majority of studies performed in Caucasians have not been large enough to compensate for the very low frequency of the $\mathrm{m} 1$ allele present compared to their Asian counterparts. Chileans are closer to Asians in relation to these polymorphisms (25). Another explanation for these discrepancies may be related to differences in linkage or genetic associations between alleles in different populations, as noted in patients of African descent who display no linkage between $M s p I$ and Ile-val polymorphisms in contrast to Asians or Caucasians (37). We previously found that the CYP1A1 polymorphism was positively associated with lung cancer alone or in combination with the GSTM1null genotype (30). In the present study, a higher frequency of the GSTM1null genotype was found in oral cancer patients in comparison to the controls. This suggests that the deletion of the GSTM1 gene causes loss of detoxification of the ultimate carcinogen resulting in a higher risk for oral cancer. In addition, our data suggest an association between the GSTM1null genotype and $\mathrm{m} 1$ polymorphism and oral cancer. Similarly to recently reported results $(8,9)$, the association values noted in the present study for GSTM1 and $\mathrm{wt} / \mathrm{m} 1$ or $\mathrm{m} 1 / \mathrm{m} 1$ in smokers were highly significant $(\mathrm{OR}=19.14, \mathrm{P}=0.003$ and $\mathrm{OR}=21.39$, $\mathrm{P}=0.0130$, respectively). Thus, an association between polymorphic CYP1A1 and the GSTM1 deletion increases the risk of oral cancer.

These results suggest that the presence of altered CYP1A1 and GSTM1 genotypes in Chilean smokers sets these individuals at a higher risk for oral cancer. This is confirmed by significantly high optical densities observed in smoking individuals carrying the $\mathrm{m} 1$ and GSTM1null genotypes (OR=19.14 and 21.39 for $\mathrm{wt} / \mathrm{m} 1 / \mathrm{GSTM} 1$ null and $\mathrm{m} 1 / \mathrm{m} 1 / \mathrm{GSTM} 1$ null combinations, respectively) indicating that smokers with both mutations may maintain higher levels of activated carcinogens (PAHs).

The high frequency of CYP1A1-altered genotypes in the Chilean groups in this study suggests that Chilean individuals are more susceptible to cancer from PAHs in tobacco than Caucasian and African-American groups. However, this susceptibility depends on the relative presence of several polymorphic enzymes, including non-phase I and phase II, in each ethnic group.

These results clearly show that the risk of oral cancer is related to the presence of unfavorable genotypes in the group of smokers. This information provides an estimation of the individual response to carcinogen exposure.

Together, our results suggest that the Chilean population, which represents an admixture between native Americans and Caucasians (mostly Spaniards), shows genetic polymorphisms in metabolic genes that have an important role in oral cancer susceptibility. In addition, our data may help to understand inter-ethnic differences in the distribution of polymorphic enzymes as well as the function of simultaneous polymorphisms in metabolic genes in each subject. To the best of our knowledge, this is the first study relating CYP1A1 and GSTM1 gene polymorphisms to oral cancer risk in smokers and non-smokers in a Chilean population group.

\section{Acknowledgements}

We thank Dr Arturo Madrid from the National Institute of Cancer for the collaboration in obtaining blood samples from patients, and Dr Hernán Vásquez for the assistance in the language editing.

\section{References}

1. Shimada T: Xenobiotic-metabolizing enzymes involved in activation and detoxification of carcinogenic polycyclic aromatic hydrocarbons. Drug Metab Pharmacokinet 21: 257-276, 2006.

2. Elovaara E, Mikkola J, Stockmann-Juvala H, Luukkanen L, Keski-Hynnilä H, Kostiainen R, Pasanen M, Pelkonen $\mathrm{O}$ and Vainio H: Polycyclic aromatic hydrocarbon (PAH) metabolizing enzyme activities in human lung, and their inducibility by exposure to naphthalene, phenanthrene, pyrene, chrysene, and benzo(a)pyrene as shown in the rat lung and liver. Arch Toxicol 81: 169-182, 2007.

3. Agúndez JA: Cytochrome P450 gene polymorphism and cancer. Curr Drug Metab 5: 211-224, 2004.

4. Shimada T and Fijii-Kuriyama Y: Metabolic activation of polycyclic aromatic hydrocarbons to carcinogens by cytochromes P450 1A1 and 1B1. Cancer Sci 95: 1-6, 2004.

5. Wright CM, Larsen JE, Colosimo ML, Barr JJ, Chen L, McLachlan RE, Yang IA, Bowman RV and Fong KM: Genetic association study of CYP1A1 polymorphisms identifies risk haplotypes in non-small cell lung cancer. Eur Respir J 35: 152-159, 2010.

6. Yang XR, Wacholder S, Xu Z, Dean M, Clark V, Gold B, Brown LM, Stone BJ, Fraumeni JF and Caporaso NE: CYP1A1 and GSTM1 polymorphisms in relation to lung cancer risk in Chinese women. Cancer Lett 214: 197-204, 2004.

7. Sreeja L, Syamala V, Hariharan S, Madhavan J, Devan SC and Ankathil R: Possible risk modification by CYP1A1, GSTM1 and GSTT1 gene polymorphisms in lung cancer susceptibility in a south Indian population. J Hum Genet 50: 618-627, 2005.

8. Cha IH, Park JY, Chung WY, Choi MA, Kim HJ and Park KK: Polymorphisms of CYP1A1 and GSTM1 genes and susceptibility to oral cancer. Yonsei Med J 48: 233-239, 2007.

9. Anantharaman D, Chaubal PM, Kannan S, Bhisey RA and Mahimkar MB: Susceptibility to oral cancer by genetic polymorphisms at CYP1A1, GSTM1 and GSTT1 loci among Indians: tobacco exposure as a risk modulator. Carcinogenesis 28: 1455-1462, 2007. 
10. Chatarjee S, Chakrabarti S, Sengupta B, Poddar S, Biswas D, Sengupta S and Taludker G: Prevalence of CYP1A1 and GST polymorphisms in the population of northeastern India and susceptibility of oral cancer. Oncol Res 17: 397-403, 2009.

11. Acevedo C, Opazo JL, Huidobro C, Cabezas J, Iturrieta J and Quiñones L: Positive correlation between single or combined genotypes of CYP1A1 and GSTM1 in relation to prostate cancer in Chilean people. Prostate 57: 111-117, 2003.

12. Little J, Sharp L, Masson LF, Brockton N, Cotton S, Haites N and Cassidy J: Colorectal cancer and genetic polymorphisms of CYP1A1, GSTM1 and GSTT1: a case-control study in the Grampian region of Scotland. Int J Cancer 119: 2155-2164, 2006.

13. Lee K, Cáceres D, Varela N, Csendes A, Ríos H and Quiñones L: Evaluation of CYP1A1 and GSTM1 as gastric cancer susceptibility biomarkers: influence of smoking habit and alcohol consumption. Rev Med Chil 134: 1107-1115, 2006.

14. Kiss I, Orsós Z, Gombos K, Bogner B, Csejtei A, Tibold A, Varga Z, Pázsit E, Magda I, Zölyomi A and Ember I: Association between allelic polymorphisms of metabolizing enzymes (CYP 1A1, CYP 1A2, CYP 2E1, mEH) and occurrence of colorectal cancer in Hungary. Anticancer Res 27: 2931-2937, 2007.

15. Quiñones L and Gil L: Induction of rat hepatic cytochrome P450 1A1 isozyme by organic extracts from airborne particulate matter. Xenobiotica 25: 571-579, 1995

16. Kawajiri K, Watanabe J, Gotoh O, Tagashira Y, Sowaga K and Fujii-Kuriyama Y: Structure and drug inducibility of human cytochrome P450c gene. Eur J Biochem 159: 219-225, 1986.

17. Kawajiri K, Nakachi K, Imai A, Yoshu N, Shimada J and Watanabe J: Identification of genetically high risk individuals to oral cancer by DNA polymorphisms of the cytochrome P4501A1 gene. FEBS Lett 263: 131-133, 1990.

18. Hayashi $S$, Watanabe J, Nakachi $K$ and Kawajiri $K$ : PCR detection of an A/G polymorphism within exon 7 of the CYP1A1 gene. Nucleic Acids Res 19: 4797, 1991

19. Crofts F, Cosma G, Currie D, Taioli E, Toniolo P and Garte S: A novel, CYP1A1 gene polymorphism in African-Americans. Carcinogenesis 14: 29-31, 1993.

20. Cascorbi L, Brockmoller J and Roots L: A C4887A polymorphism in exon 7 of human CYP1A1: population frequency, mutation linkages and impact on oral cancer susceptibility. Cancer Res 56: 4965-4969, 1996.

21. Aynacioglu A, Cascorbi I, Ozikiewicz P and Roots I: High frequency of CYP1A1 mutations in a Turkish population. Arch Toxicol 72: 215-218, 1998.

22. Magno LA, Talbot J, Talbot T, Borges Santos AM, Souza RP Marin LJ, Moreli ML, de Melo PR, Corrêa RX, Rios Santos F and Di Pietro G: Glutathione s-transferase variants in a Brazilian population. Pharmacology 83: 231-236, 2009.

23. Bailliet G, Santos MR, Alfaro EL, Dipierri JE, Demarchi DA, Carnese FR and Bianchi NO: Allele and genotype frequencies of metabolic genes in Native Americans from Argentina and Paraguay. Mutat Res 627: 171-177, 2007.

24. Torres MM, Acosta CP, Sicard DM and Groot de Restrepo H: Genetic susceptibility and risk of gastric cancer in a human population of Cauca, Colombia. Biomedica 24: 153-162, 2004.

25. Quiñones L, Berthou F, Varela N, Simon B, Gil L and Lucas D: Ethnic susceptibility to lung cancer: differences in CYP2E1, CYP1A1 and GSTM1 genetic polymorphisms between French Caucasian and Chilean populations. Cancer Lett 141: 167-171, 1999.
26. Seidegard J, Vorachek W, Pero R and Pearson W: Hereditary differences in the expression of the human glutathione transferase active on trans-stilbene oxide are due to a gene deletion. Proc Natl Acad Sci USA 85: 7293-7297, 1998.

27. Lin H-J, Han C-Y, Bernstein DA, Hsiao W, Lin B and Hardy S: Ethnic distribution of the glutathione transferase $\mathrm{Mu} 1-1$ (GSTM1) null genotype in 1473 individuals and application to bladder cancer susceptibility. Carcinogenesis 15: 1077-1081, 1994.

28. Linhares JJ, Da Silva ID, De Souza NC, Noronha EC, Ferraro O, De Carvallo CV and Bacarat FF: Genetic polymorphism of GSTM1 in women with breast cancer and interact with reproductive history and several clinical pathologies. Biol Res 38: 273-281, 2005

29. Boccia S, Sayed-Tabatabaei FA, Persiani R, Gianfagna F, Rausei S, Arzani D, La Greca A, D'Ugo D, La Torre G, van Duijn CM and Ricciardi G: Polymorphisms in metabolic genes, their combination and interaction with tobacco smoke and alcohol consumption and risk of gastric cancer: a case-control study in an Italian population. BMC Cancer 7: 206, 2007.

30. Quiñones L, Lucas D, Godoy J, Cáceres D, Berthou F, Varela N, Lee K, Acevedo C, Martínez L, Aguilera AM and Gil L: CYP1A1, CYP2E1 and GSTM1 genetic polymorphisms. The effect of single and combined genotypes on lung cancer susceptibility in Chilean people. Cancer Lett 174: 35-44, 2001.

31. Lira MG, Provezza L, Malerba G, Naldi L, Remuzzi G, Boschiero L, Forni A, Rugiu C, Piaserico S, Alaibac M, Turco A, Girolomoni $\mathrm{G}$ and Tessari G: Glutathione S-transferase and CYP1A1 gene polymorphisms and non-melanoma skin cancer risk in Italian transplanted patients. Exp Dermatol 15: 958-965, 2006.

32. Yoshida K, Osawa K, Kasahara M, Miyaishi A, Nakanishi K, Hayamizu S, Osawa Y, Tsutou A, Tabuchi Y, Shimada E, Tanaka K, Yamamoto $M$ and Takahashi J: Association of CYP1A1, CYP1A2, GSTM1 and NAT2 gene polymorphisms with colorectal cancer and smoking. Asian Pac J Cancer Prev 8: 438-444, 2007

33. Caceres D, Iturrieta J, Acevedo C, Huidobro C, Varela N and Quiñones L: Relationship among metabolizing genes, smoking and alcohol use as modifier factors on prostate cancer risk: Exploring some gene-gene and gene-environment interactions. Eur J Epidemiol 20: 79-88, 2005.

34. Das BR and Nagpal JK: Understanding the biology of oral cancer. Med Sci Monit 8: RA258-RA267, 2002.

35. Riera P and Martínez B: Morbidity and mortality for oral and pharyngeal cancer in Chile. Rev Med Chil 133: 555-563, 2005.

36. Ambrosone C, Freudenheim J, Oraham S, Marshall J, Vena J, Brasure J, Laughlin R, Nemoto T, Michalek A, Harrington A, Ford T and Shields P: Cytochrome P4501A1 and glutathione S-transferase (Ml) genetic polymorphisms and postmenopausal breast cancer risk. Cancer Res 55: 3483-3485, 1995.

37. Garte S: The role of ethnicity in cancer susceptibility gene polymorphisms: the example of CYP1A1. Carcinogenesis 19: 1329-1332, 1998. 
